\title{
Engineering Management Based on the Reduction of Carbon Dioxide Emissions: a Review
}

\author{
Zhe Zhang $^{1 *}$, Jiuping $\mathrm{Xu}^{2}$
}

\begin{abstract}
.
The pollution on the ground caused by engineering development has long been recognized as threats to populations and ecosystems, and is being actively tackled through engineering management. In this paper, we present a systematic framework to categorize existing research work on the reduction of carbon dioxide emissions constraints through review the literature in engineering management field. Our goals are aim to answer three research questions:

$\rightarrow R Q 1$ : Which engineering project or industry engineering requiring special attentions in the reduction of carbon

dioxide emissions constraints for the goal of sustainable development?

$\rightarrow$ RQ2: What research methods have been used in engineering management on the basis of the reduction of carbon dioxide emissions constraints?

$\rightarrow$ RQ3: Which key mitigation technologies and practices, measures, instruments and policies of engineering management are shown to be environmentally effective to the reduction of carbon dioxide emissions?

In addition, we also summarize past research contents and approaches, and identify the future perspective of engineering management based on the reduction of carbon dioxide emissions constraints.
\end{abstract}

Keywords: carbon dioxide emissions, engineering management, global warming, sustainable development, systematic literature review

\section{Introduction}

Nowadays, there is a growing awareness of the pollution generated by engineering development, and this pollution has created damage to the ecology and climate change all over the world, see Fig. 1. Since more engineering projects imply more carbon dioxide $\left(\mathrm{CO}_{2}\right)$ emissions, serious attention has to be paid and precautions need to be taken before the disasters occur. In this case, the practical engineering development must consider $\mathrm{CO}_{2}$ mitigation in an effective engineering management. Simply put, we need to mitigate the emissions of carbon dioxide through appropriate engineering management for the earth sustainability.

Though Kyoto Protocol has been signed in December 1997, the world is still engaged in debating whether or not climate change has taken place, or even doubt that it is humaninduced. Even if the debate may still go on, climate change has become an internationally recognized problem. In fact, it is conformed that climate change is real and it is caused by human activities partly (UNDP, 2007). According to the fourth report of IPCC (Intergovernmental Panel on Climate Change), the next ten years will be critical for

${ }^{1}$ School Economics \& Management, Nanjing University of Science and Technology, Nanjing 210094, CHINA. *Corresponding author.

${ }^{2}$ Engineering Research Center of Low Carbon Technology and Economy, Sichuan University, Chengdu 610064, CHINA. 
the world in light of the long-term greenhouse gas emissions stabilization scenario (490ppmv CO2) (Fisher et al., 2007). In order to avoid catastrophic climate change, the world requires the reduction in global emissions from 2015 onwards, and the goal of reduction amount is set to be less than 50\% of today's level by 2050. To attain this goal, 192 countries come together to discuss how to reduce carbon emissions in December 2009 at Copenhagen, and to resolve the global climate change problem together.

In this paper, we will present a systematic review of engineering management based on the reduction of carbon dioxide emissions constraints. Our goals are: (1) to provide an overview of empirical studies within this field, (2) to summarize past research contents and approaches, (3) and to point out the future perspective. In order to achieve these goals, we employ the systematic literature review approach which proposed by Kitchenham et al. (2004). This systematic literature review allows us to evaluate and interpret all existing research that is relevant to our study. In addition, it allows us identify reliably where the literature has recurring themes, where it presents

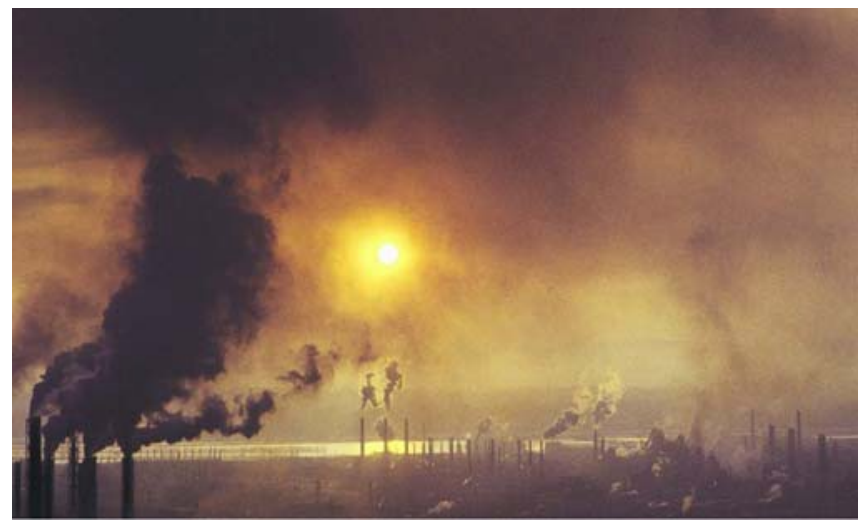

Fig. 1. The effect of the Sun is already dampened by atmospheric pollution (Oliver, 2007)

conflicting findings, and where are there gaps in the existing body of work.

The remainder of this article is organized as follows. In Section 2, we present the research background and motivations of this review. Then, we describe the research method that we used to select and review the literature for our research in section 3, along with our chosen framework for analysis. Subsequently, in section 4, we propose the results of the systematic review according to the framework. In Section 5, we discuss engineering projects or industry engineering need special concern, and research methods and of engineering management in details. We present the trend and future perspective in Section 6 and conclude the paper in Section 7.

\section{Research Background and Motivations}

Global warming is a global environmental concern with potentially significant consequences for the society. The Copenhagen Accord has underlined that climate change is one of the greatest challenges of our time once again. Over the past three decades, the GISS (Goddard Institute for Space Studies) surface temperature record 
shows an upward trend of about $0.2^{\circ} \mathrm{C}\left(0.36^{\circ} \mathrm{F}\right)$ per decade. Fig. 2 shows the 10-year average temperature anomaly relative to the 1951-1980 mean. The largest temperature increases are in the Arctic and the Antarctic Peninsula. Scientists predict that by 2100, the Northern Hemisphere temperatures will rise by $5^{\circ} \mathrm{C}$, but by the new formula, rising temperatures may reach $8^{\circ} \mathrm{C}$, see Guardian (2009). A warming of the Earth is that it could result in major impacts such as hurricanes, floods, droughts, food production, and species extinction. Which is the key factor that causes global warming? In fact, scientists had realized that gases in the atmosphere cause a "greenhouse effect" which affects the planet's temperature in the 19th century. Fig. 4 shows the level of $\mathrm{CO}_{2}$ in the atmosphere from

1958 to 2007 . The curve has been climbing exponentially (except in the mid 1990s when the economy of Eastern Europe and the Soviet Union collapsed). The amount of gas added to the atmosphere is doubling every 30-35 years. From Fig. $2 \sim$ Fig. 4, we can obtain the relationship between climate change and $\mathrm{CO}_{2}$ emissions very clearly. Therefore, in order to avoid dangerous climate changes, we must take positive and effective measures to mitigate $\mathrm{CO}_{2}$ emissions.

The fact that human activities have a discernible impact on global climate systems is the scientific consensus

nowadays. When we develop the engineering projects and industry engineering, we are releasing carbon dioxide into the atmosphere, thereby increasing our effect on the environment in the form of global warming and climate change. To avoid these disasters, we should be concerned will what the key $\mathrm{CO}_{2}$ contributors are. For example, considering the carbon dioxide emissions in Singapore (Fig. 5), we can see that "Industry" plays the most important role in six key $\mathrm{CO}_{2}$ contributors (54\%), and "Electricity", "Transport" and "Buildings" also deserve serious attention. All of four key $\mathrm{CO}_{2}$ contributors belong to the scope of engineering, so effective engineering management could mitigate the emission of $\mathrm{CO}_{2}$.

Based on above, we know that engineering projects and industry engineering are the main factors of the

emission of $\mathrm{CO}_{2}$. Therefore, in order to avoid serious disasters and in the context of sustainable development requirement, the reduction of carbon dioxide emissions as constraints should be required special concern in engineering management. 


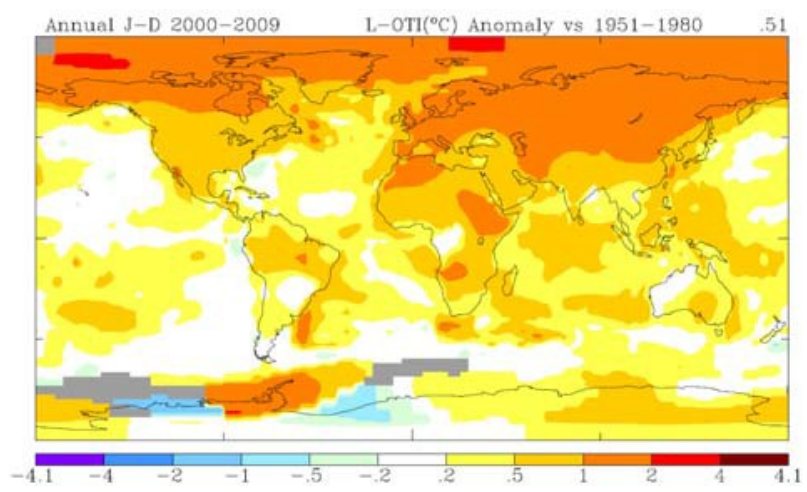

Fig. 2. 2000-2009 average temperature

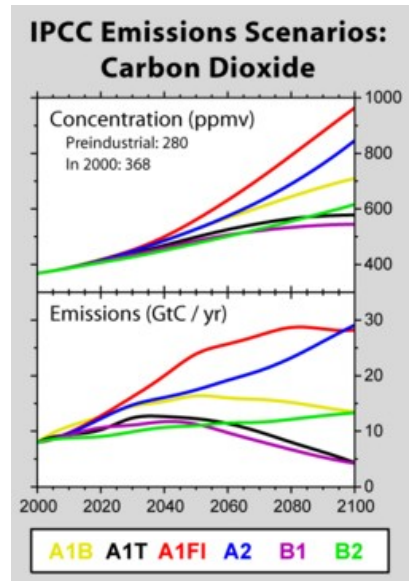

Fig. 4. Monthly average Carbon Dioxide

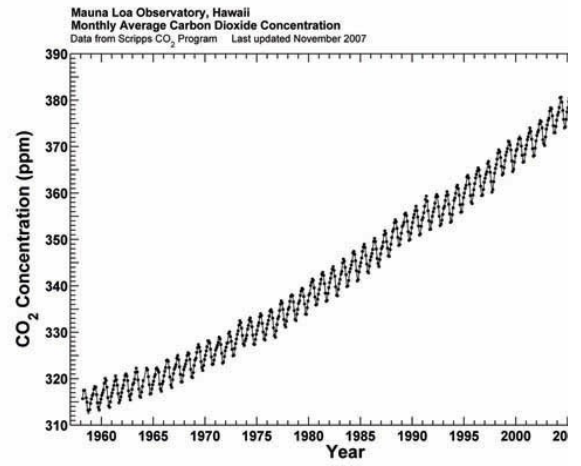

Fig. 3. Monthly average Carbon Dioxide concentration

(Source: NASA/GISS) (Source:

Scripps Institution of Oceanography)

Key $\mathrm{CO}_{2}$ Contributors (2005) (kilo tonnes)

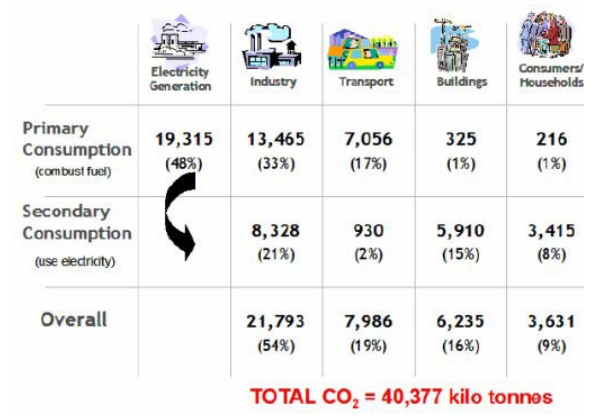

Fig. 5. Key $\mathrm{CO}_{2}$ contributors (Source: National Climate concentration (Source: IPCC) Change Strategy)

\section{Systematic Review Method}

As the primarily approach concerned with the problem of aggregating empirical evidence, systematic reviews become more and more popular in recently, see Horvath and Pewsner (2004), Khan (2005), Davis et al. (2006), Hannay and Sjoberg (2007), Brereton et al. (2007), Dyba et al. (2007), Blanco et al. (2008), Tricco et al. (2008), Sampson et al. (2008), Nicolas and Toval (2009), and so on. Systematic literature review is the method of identifying, evaluating and interpreting all available research relevant to a particular research question, or topic area, or phenomenon of interest. It requires considerably more effort than traditional reviews. Compared with traditional reviews, systematic literature reviews have two major advantages: one is that they provide information about the effects of some phenomenon across a wide range of settings and empirical methods. If studies give consistent results, systematic reviews provide evidence 
that the phenomenon is robust and transferable. If the studies give inconsistent results, sources of variation can be studied. Another, in the case of quantitative studies, it is possible to combine data using meta-analytic techniques (Kitchenham, 2004; Dyba et al., 2007). The advantages of systematic reviews compared with traditional reviews are show in Table. 1.

Table. 1: The advantages of systematic reviews compared with traditional reviews (Adapted from Mulrow and Cook, 1998)
\begin{tabular}{|lll|}
\hline Feature & Traditional reviews & Systematic reviews \\
\hline Question & Often broad in scope & Often a focused research question \\
Identification research & Not usually specified, potentially biased & Comprehensive sources and explicit search strategy \\
Selection & Not usually specified, potentially biased & Criterion-based selection, uniformly applied \\
Appraisal & Variable & Rigorous critical appraisal \\
Synthesis & Often a qualitative summary & Qualitative and/or quantitative synthesis \\
Inferences & Sometimes evidence-based & Usually evidence-based \\
\hline
\end{tabular}

In this study, the review method is the systematic review presented by Kitchenham (2004). In accordance with systematic review guidelines, we give the systematic review process in Fig. 6. In order to avoid overlook any important research, additional searches are performed directly on key conference proceedings, journals and authors. Furthermore we conduct a secondary search based on references found in our primary studies.

\subsection{Specifying research questions and planning the review}

For the systematic review, we develop the protocol, the search strategy and criteria for the inclusion and exclusion, and method of synthesis. Then, we specify the process and methods that we apply. The aim of the method is to provide an overview for the research of the reduction of carbon dioxide emissions constraints in engineering management, and answer the three research questions listed in Section 1.

\subsection{Identification of relevant research}

In this paper, we start the systematic search with the identification of keywords and search terms. Our three research questions contain the following key words: engineering, engineering project, engineering management, reduction, carbon dioxide emissions, and sustainable development. On the basis of

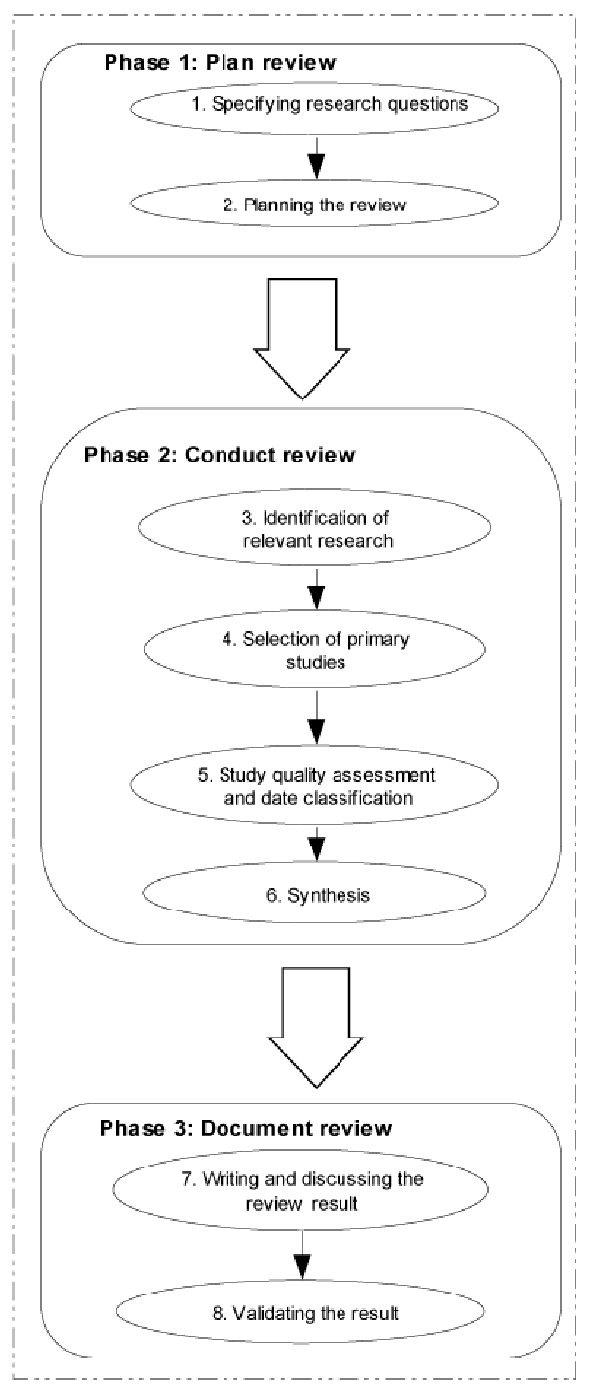

Fig. 6 Systematic review process 
these keywords, for engineering management, we choose "Engineering Management", "Civil Engineering", "Steel Industry",

"Electric Power", “Fossil Fuel Combustion", “Hydropower", “Waste Combustion ", "Transportation Systems",

"Cement Industry", "Agricultural Engineering", and "Forestry Engineering" as the search terms, because the engineering fields above account for a large proportion in carbon dioxide emissions. Besides, in order to make a broader search scope, we select "Project management" as one of keywords.

For the reduction of carbon dioxide emissions, we choose "Carbon Dioxide Emissions", "Greenhouse Gas",

"Global Warming", "Climate Change", and "Sustainable Development". For enhancing completeness, we use the keywords showed in Table. 2. In this study, we consider five electronic bases, showed in Table. 3 .

Table. 2: Keywords for the systematic review

\begin{tabular}{|l|l|l|}
\hline Terms for & & Terms for \\
$\diamond$ Engineering Management or & & $\bullet$ Carbon Dioxide Emissions or \\
$\diamond$ Project Management or & & $\bullet$ Greenhouse Gas Emissions or \\
$\diamond$ Energy Engineering or & & $\bullet$ Global Warming or \\
$\diamond$ Iron and Steel Industry or & & $\bullet$ Climate Change or \\
$\diamond$ Forestry Engineering or & and & $\bullet$ Sustainable Development \\
$\diamond$ Construction Engineering or & & \\
$\diamond$ Waste Engineering or & & \\
$\diamond$ Transportation Engineering or & & \\
$\diamond$ Cement Industry or & \\
$\diamond$ Agricultural Engineering or & & \\
\hline
\end{tabular}

Table. 3: Sources of systematic reviews

\begin{tabular}{|l|l|}
\hline \multicolumn{1}{|c|}{ Source } & \multicolumn{1}{c|}{ Address } \\
\hline ISI Web of Science & http://isiknowledge.com \\
EI Compendex & http://www.engineeringvillage.org \\
ScienceDirect & http://www.sciencedirect.com/ \\
Emerald & http://www.emeraldinsight.com/ \\
Wiley-BlackWell e-journals & http://www.interscience.wiley.com \\
\hline
\end{tabular}

The research is performed in October 2014, so we select the research published from 1980 to October 2014 (ISI Web of Science from 1986 to October 2014). The identification process yields 9352 articles (see Fig. 7), and they form the basis for the next step in our selection process ${ }^{1}$.

1 Note: As the number of the articles is too large, so we only select the articles that the keywords are in the "title, abstract, keywords". 


\subsection{Selection of primary studies}

After identifying the articles, we select the papers according to the exclusion criteria as follows:

$3 / 4 \quad$ Duplicate articles. There are some duplicate publications belong to more than one database, so we remove the duplication. Through this process, the number of articles reduces to 7864 .

$3 / 4 \quad$ Conference presentations. We eliminate the conference presentations and the number of articles reduces to

6627.

$3 / 4$ Description of book and journal. We eliminate the description of book and journal, and the number reduces to 5286 .

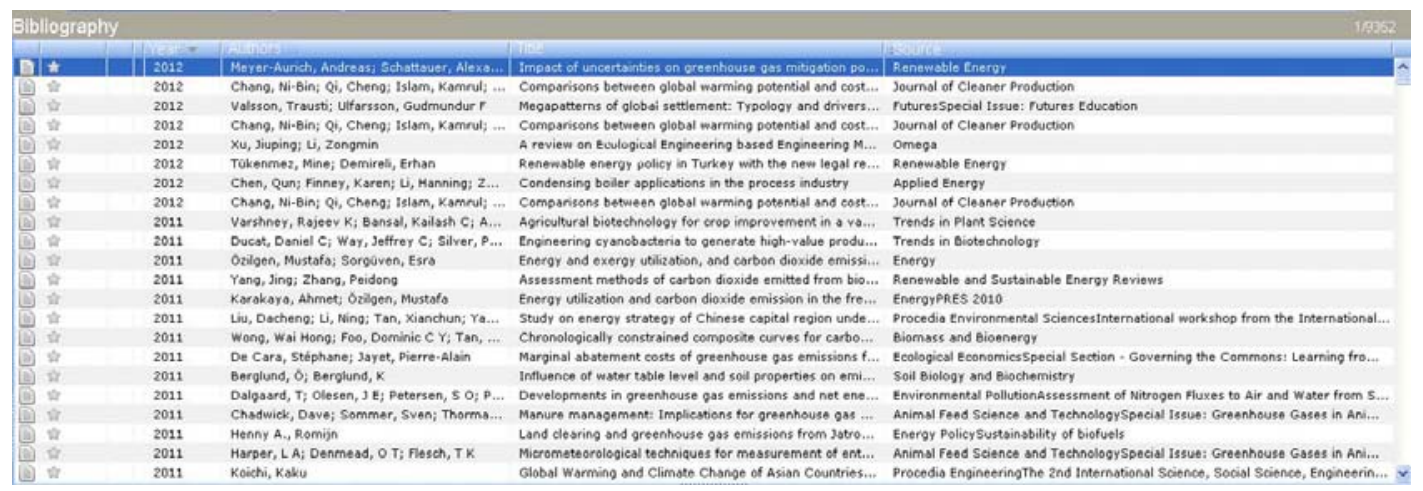

Fig. 7. The basis data of systematic review process

These 5286 literatures make up the initial document database. However, the number of the document is still too large, so we include texts that:

$z \quad$ Solve engineering problems from a management perspective not from a pure technical perspective. We enter the keywords "Management" to the initial document database, and then we get 1032 documents.

$z$ Consider the background of this research. We enter the keywords "Carbon Dioxide Emissions",

"Greenhouse Gas Emissions", “Global Warming", “Climate Change ", and "Sustainable Development" to

1032 documents, then delete the other articles. The number of articles reduces to 643 .

$z$ Answer any one or more of our research questions directly or indirectly. Consider the three research questions listed in Section 1 as the criteria for selecting articles, we read through the title and abstract of 643 documents, and select 206 articles as the final document database.

By the six criterions above, the final number of papers selected for this review is $206,2.20 \%$ of initial document database.

\subsection{Study quality assessment, data classification and synthesis}

Now, 206 studies are selected for this review. We settle on a simpler classification of the studies by examining the scientific rigor. Then, we assess the 
quality of the selected papers by categorizing these into empirical studies, lessons learned reports and either reviews of the literature or secondary studies. The criterion for being accepted as an empirical study is that the article has a section at least describing the research method and context. After the quality assessment, we have 175 empirical studies, 23 reports of lessons learned and 8 literature reviews. Fig. 8 shows that out of the 206 studies, $84.95 \%$ are empirical, i.e. findings are based on direct evidence or experiment. The $11.17 \%$ lessons learned reports and a small number of studies $(3.88 \%)$ that are either reviews of the literature or secondary studies, where empirical work is reexamined.

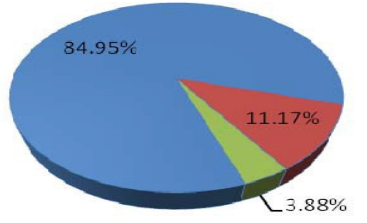

Empirical Studies

Lessons Learned Reports

$\square$ Literature Reviews
Fig. 8. Types of studies in the accepted papers

For synthesizing data, we choose to only use the papers classified as empirical studies in our

framework, in order to avoid problems associated with lessons learned reports stemming from their lack of scientific rigor. We extract main findings and the research method for each article. Both technical process and technical management process are considered in this review.

\section{Review Results and Findings}

After the systematic review execution, we classify the final document storage. The statistical results of articles from the final document storage are shown in Table. 4.

Table. 4: The overall findings of articles from empirical studies

\begin{tabular}{|c|c|}
\hline Theme & Results \\
\hline Article Type & Conference proceedings: 16 (9.14\%); Journal Articles and Books: $159(90.86 \%)$ \\
\hline Researchers & $\begin{array}{l}\text { Authors who published } 7 \text { include: Christensen T. }([33,34,97,47,79,40,48]) \\
\text { Authors who published } 4 \text { include: Gentil E. ([33, 47, 48, 127]) } \\
\text { Authors who published } 2 \text { include: Amon B. and Kryvoruchko V. }([17,18]) \text {, Kjeldsen P. ([127, 21]), } \\
\text { Huang G. ([86]), etc. }\end{array}$ \\
\hline Year of Study & $\begin{array}{l}\text { 1980-1991: } 1(0.57 \%) ; 1992-1994: 6(3.43 \%) ; 1995-1997: 8(4.57 \%) ; 1998-2000: 14(8.00 \%) ; 2001-2003: 22(12.57 \%) ; \\
\text { 2004-2006: } 31(17.71 \%) ; 2007-2009: 67(38.29 \%) ; \text { After } 2010 \text { (Only contains } 2010 \text { - October 2011, including Inpress } \\
\text { article): } 26(14.86 \%)\end{array}$ \\
\hline Key Journals & $\begin{array}{l}\text { Renewable and Sustainable Energy Reviews: } 12(6.86 \%) \text {; Climatic Change: } 11(6.29 \%) \text {; Energy Policy: } 10(5.71 \%) \text {; } \\
\text { Environmental Science \& Policy: } 10 \text { (5.71\%); Applied Energy: } 6(3.43 \%) \text {; } \\
\text { Transportation Research Part D: Transport and Environment: } 5(2.86 \%) \text {; Global Environmental Change: } 5(2.86 \%) \text {; } \\
\text { Journal of Environmental Management: } 5(2.86 \%) \text {; Atmospheric Environment: } 3(1.71 \%) \text {, Energy: } 3(1.71 \%)\end{array}$ \\
\hline
\end{tabular}

\subsection{Temporal view of publications}

Fig. 9 shows that over the last 30 years there is a recent increase in published papers covering engineering management based on the reduction of carbon dioxide emissions constraints ${ }^{2}$. This increase may be a reflection of a growing awareness of the serious situation of global warming. Alternatively, this increase may just match a general rise in published papers in this area.

2“After 2010": Only contains 2010 -- October 2014, including Inpress article. 


\subsection{Data sources}

Fig. 10 gives a breakdown of where our 175 empirical studies are published. The majority are published in "Renewable and Sustainable Energy Reviews", "Climatic Change", "Energy Policy" and "Environmental

Science \& Policy".

\subsection{Research Question 1}

Seventy-four papers are identified as answering Research Question 1 (RQ1), and the findings suggest that all eight engineering projects and industry engineering are closely related to carbon

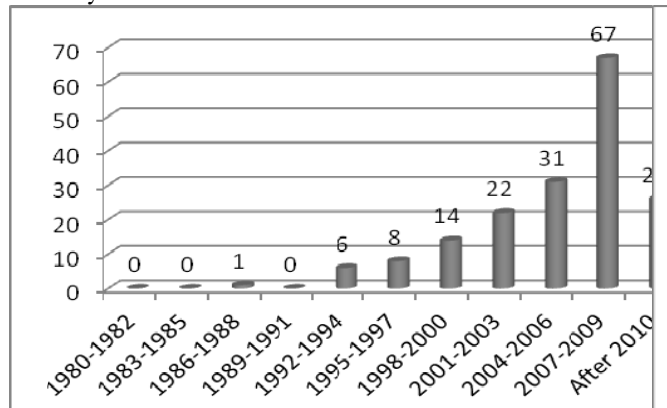

Fig. 9. Number of papers included in the review

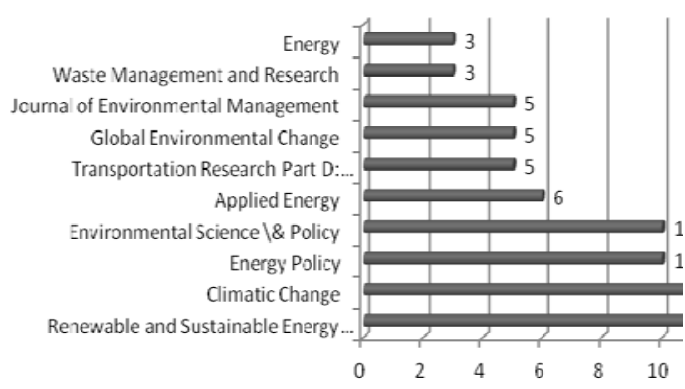

Fig. 10. Publication sources of empirical studies by 3 years intervals

dioxide emissions, especially Energy Engineering (Frequency: 19; Proportion: $25.67 \%{ }^{3}$ ), Iron and Steel Industry

(Frequency: 11; Proportion: 14.86\%), Cement Industry (Frequency: 10; Propo- rtion: 13.51\%) and Transportation

Engineering (Frequency: 10; Proportion: 13.51\%) (Fig. 11).

From Table 5, we can see that there are thirteen research methods have been used in engineering management on the basis of the reduction of carbon dioxide emissions constraints in 175 empirical studies, i.e. Dynamic Integrated Model of Climate and the Economy (DICE), Inexact Dynamic Optimization Model, System Dynamics Approach, Decision Inventory Approach, Decision Matrix Approach, Municipal Energy Systems Planning Model, Mental Models Approach, MARKAL-LITE Model, Consistent Approach, Input-Output Approach, Integrated Approach, Collaborative Approach and Energy Systems Planning Model.

\subsection{Research Question 3}

In this study, fifty-two papers are identified as answering Research Question 3 (RQ3). Sector, key mitigation technologies and practices, measures, instruments and policies, and reference for Research Question 3 are shown in Table. 6.

\footnotetext{
As some articles appeared several times in different engineering project categories, the proportion of frequency

$=19 / 74=25.67 \%$.
} 


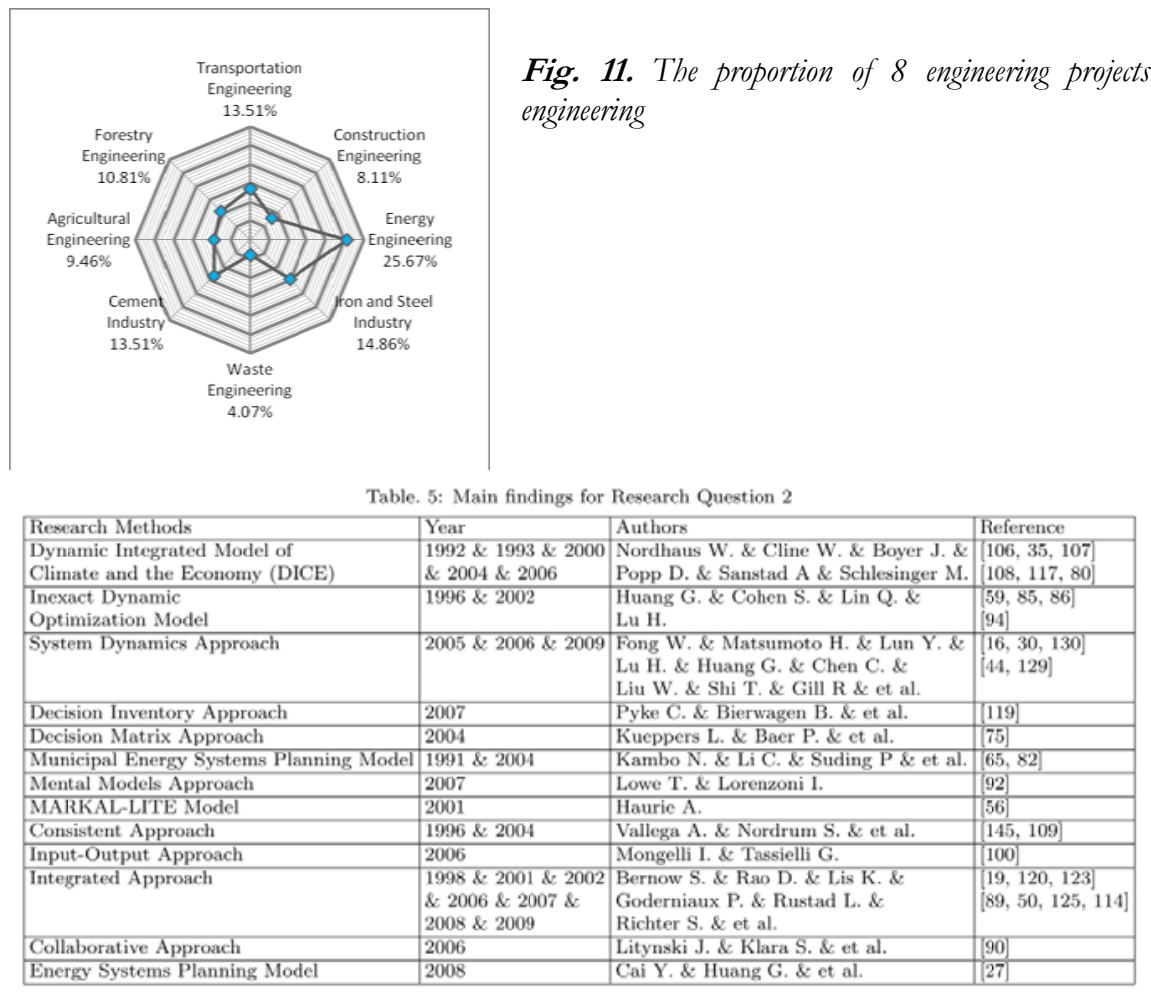

\section{Discussion}

Based on the above review results and findings of systematic review, we will discuss engineering projects or industry engineering need special concern, and research methods and of engineering management in details.

\subsection{Engineering projects and industry engineering need special concern}

As the main findings about RQ1 in Section 4, we know that Energy Engineering, Iron and Steel Industry, Cement Industry, Transportation Engineering should be required special concern.

\subsection{Energy Engineering}

As seen in Fig. 12, 25.67\% of literature is focused on energy engineering, especially energy supply. Actually, from Fourth Assessment Report (AR4) of Intergovernmental Panel on Climate Change (IPCC), we can know that energy supply is the largest contributor of $\mathrm{CO}_{2}$ emissions in all sectors (25.9 percentage) (Fig. 12).

Consequently, a lot of studies have looked into reducing $\mathrm{CO}_{2}$ emissions in energy engineering. Liu et al.

(2011) analysis the characteristics of energy supply and energy consumption in Beijing, which is expected to both keep higher GDP growth than average and cut unit GDP 
carbon emission as the capital and one of the biggest cites in China. By the economicenergy-environment-oriented reference energy system (RES), MARKAL optimal model and multi-period linear programming matrix, the study obtains the suitable energy supply structure and end-use technology structure of Beijing. Sinyak and Nagano (1994) analyze long-term energy prospects from the point of view of future carbon dioxide emissions and constraints imposed by possible changes in the global climate, and evaluate the consequences of various policy options in energy supply and demand to understand the efficacy of different measures in approaching a global greenhouse-gasabatement energy policy. Kato et al. (2011) introduce a new energy system, called Active Carbon Recycling Energy System (ACRES), to reduce carbon dioxide emissions and the establishment of carbon supply security. Utamura (2005) propose an analytical model to account for carbon dioxide emission behavior during replacement of power source from fossil fuel to renewable energy in which sustainability of energy supply is stressed. Analysis show that energy payback time (EPT) should be much shorter than the doubling time of manufacturing cycle to secure adequate available energy during the replacement, and a nuclear plant, small hydropower plant, wind power plant and photovoltaic cell are taken as representative candidates and investigated as options to replace fossil power until toward the end of this century. Ou et al. (2011) use the Well-toMeter (WTM) analysis module in the Tsinghua-CA3EM model to examine the primary fossil energy consumption (PFEC) and greenhouse gas (GHG) emissions for electricity generation and supply in China. They conclude that the current high levels of PFEC and GHG emission for electricity in China are largely due to the dominant role of coal in the power-generation sector and the relatively low efficiencies during all the sub-stages from resource extraction to final energy consumption, and the development of nuclear and renewable energy as well as low carbon technologies such as carbon dioxide capture and storage (CCS) can significantly reduce GHG emissions from electricity.

Numerous studies of reducing $\mathrm{CO}_{2}$ emissions in energy engineering indicate that state policy makers, engineering decision makers, electric and gas utilities, energy customers, and other key stakeholders should focus on renewable energy and clean energy. Only by identifying, designing and implementing renewable energy and clean energy policy, effective energy engineering management and technology solutions, we will deliver important environmental and economic benefits from energy engineering in the reduction of $\mathrm{CO}_{2}$ emissions. 


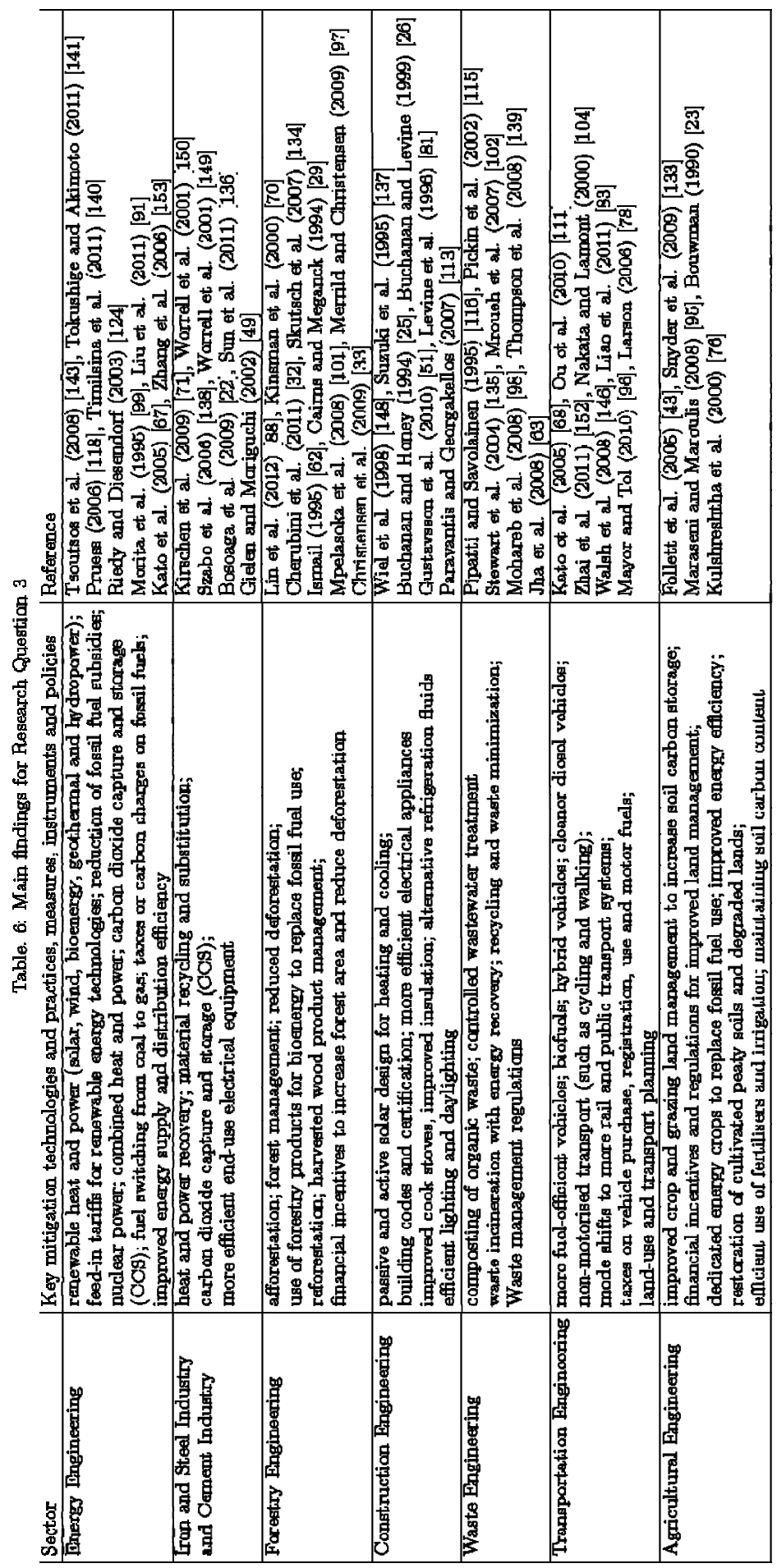




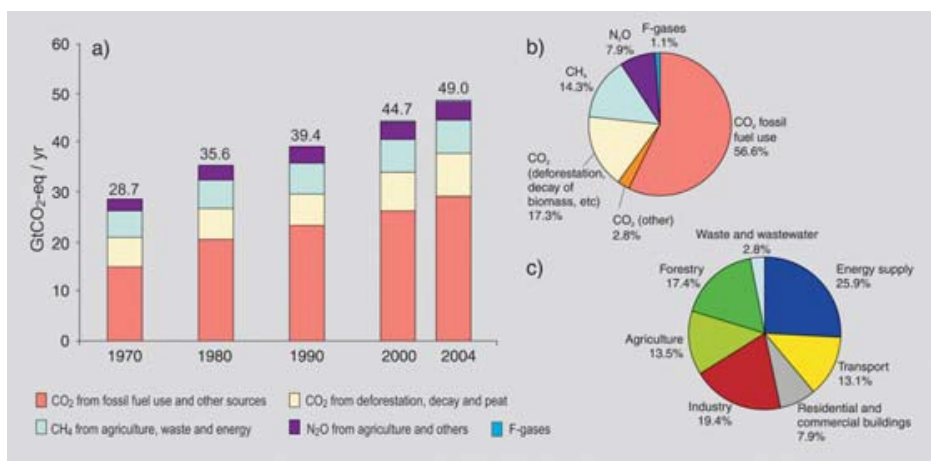

Fig. 12. Global anthropogenic GHG emissions (CO2 eq.) in 2004 (Source: IPCC)

\subsubsection{Iron and Steel Industry}

There is $14.86 \%$ literature focuses on the iron and steel industry. As one of the most energy intensive industries, iron and steel industry contribute in global $\mathrm{CO} 2$ emissions. IPCC points that the production of iron and steel is the third largest contributor of $\mathrm{CO}_{2}$ emissions in industry (after cement production and refining). So as one of the most important sources, iron and steel industry should be required more attention in the reduction of $\mathrm{CO}_{2}$ emissions.

As the often used approach in carbon emission factors, logarithmic mean Division index (LMDI) play an important role in the research of $\mathrm{CO}_{2}$ emissions in iron and steel Industry. For example, by LMDI technique, Sun et al. (2011) decompose total change in $\mathrm{CO}_{2}$ emissions into four factors: emission factor effect, energy structure effect, energy consumption effect, and steel production effect. And prove that steel production effect is the major factor which is responsible for the rise in $\mathrm{CO}_{2}$ emissions; whereas the energy consumption effect contributes most to the reduction in $\mathrm{CO}_{2}$ emissions. Hatzigeorgiou et al. (2010) present the decomposition analysis of energy-related CO2 emissions in Greece and in the EU-25 from 1990 to 2020, by means of the LMDI technique and a baseline scenario approach based on the PRIMES simulation modeling system for energy demand and supply. In this study, by LMDI, changes in $\mathrm{CO}_{2}$ emissions are decomposed into four factors: income effect, energy intensity effect, fuel share effect, and population effect. Using LMDI, Sheinbaum et al. (2009) analyze changes in energy use and carbon dioxide emissions in Mexico's iron and steel industry from 1970-2006, and examine CO2 emissions related to energy use and production process. Results show that $\mathrm{CO}_{2}$ emissions from fuel consumption and iron and steel production process increased by $134 \%$, and in addition to structure and efficiency, fuel share effect also drove down emissions by $4.2 \%$ in the entire period.

While, other researchers focus on some mathematical methods. Gielen and Moriguchi (2002) develop a new linear programming model, named Steel Environmental strategy Assessment Program, to analyze of $\mathrm{CO}_{2}$ emission reduction potentials in the Japanese iron and steel industry. The model can be used to analyze the impact of $\mathrm{CO}_{2}$ taxes on technology selection, iron and steel trade and product demand for the next three decades. The Japanese iron and steel industry accounts for approximately $15 \%$ of the 
Japanese greenhouse gas emissions. The model results suggest that these emissions will decline from a level of $185 \mathrm{Mt}$ in 2000 to about 150Mt in 2020-2030 because of declining production and increasing recycling, and if only Japan and Europe would introduce such a tax, Japanese emissions will decline to $25 \mathrm{Mt} \mathrm{CO} 2$. Wang et al. (2007) analyze the scenario on $\mathrm{CO}_{2}$ emissions reduction potential in China's iron and steel industry by the model using LEAP software. Three different $\mathrm{CO}_{2}$ emission scenarios are generated for China's iron and steel industry from 2000 to 2030. They conclude that emissions reduction will rely more on the adjustment of production processes and the application of more modern

large scale plants taking a long term perspective. Besides, advanced blast furnace technology will inevitably play an important role. Hidalgo et al. (2005) present a recursive world simulation model-- the Iron and Steel Industry Model (ISIM) -- to analyze the evolution of the industry from 1997 to 2030. ISIM focuses on steel production, demand, trade, energy consumption, $\mathrm{CO}_{2}$ emissions, technology dynamics, and retrofitting options, and gives an outlook on the evolution of the iron and steel industry in the 1997-2030 periods.

Besides, Ren and Wang (2011) investigate the development status of iron and steel industry in Shandong province in response to the energy-saving and emission-reduction policy in China, and propose four measures-- improving the technical equipment and equipment capacity, optimizing process, decreasing iron-steel ratio and optimizing energy structure-- to realize the target of sustainable and low-carbon economic development in Shandong's iron and steel industry. Si et al. (2011) analysis the feasibility of waste heat recovery and assesses energy efficiency at a steel company, Gerdau Ameristeel in Selkirk, Manitoba.

\subsubsection{Cement Industry}

There is $13.51 \%$ of literature is focused on cement industry. Cement is one of the most widely used construction materials, and the type of fuel used (especially coal) in cement production impacts on $\mathrm{CO}_{2}$ emissions directly. It has been proved that cement industry accounts for approximately $5 \%$ of current global man-made $\mathrm{CO}_{2}$ emissions (Cagiao et al., 2011), see Fig. 13. In 2006, the global $\mathrm{CO}_{2}$ emissions in cement industry are about

1.88Gt. If no measures are taken, with the continued growth of global cement production, it is expected to rise to

2.34Gt by 2050 at least (International Energy Agency). Thence, there is growing awareness that cement industry is a significant contributor to carbon dioxide emitted and great concern has to be tack led (Rehan and Nehdi, 2005).

To data, International Energy Agency (IEA), Cement Sustainability Initiative (CSI) and European Cement Research Academy (ECRA), have already drafted the cement industry roadmap targets in global $\mathrm{CO}_{2}$ emissions (Fig. 15). They agree that technology of reducing carbon emissions from cement industry should follow four ways: (1) Energy efficiency, (2) Alternative fuel use and fuel switching, (3) Clinker substitution, (4) Carbon capture and storage.Besides, emerging environmental policies also should be considered. 
From Fig. 14, we can see that $\mathrm{CO}_{2}$ emissions in cement industry may about $1.55 \mathrm{Gt}$ by 2050 by four effective measures above, 18\% decrease compared with 2006 . The four means of carbon reduction contribution rates are as follows:

Energy efficiency

$10 \%$, Alternative fuel use and fuel switching 24\%, Clinker substitution 10\%, Carbon capture and storage $56 \%$.

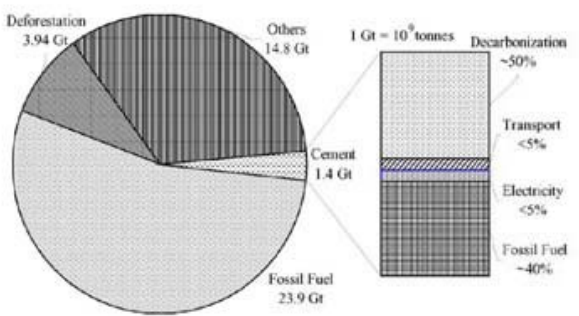

Fig. 13. Global GHG emissions (CO2 eq.) and the contribution of cement production (data from Humphreys and Mahasenan, 2002)

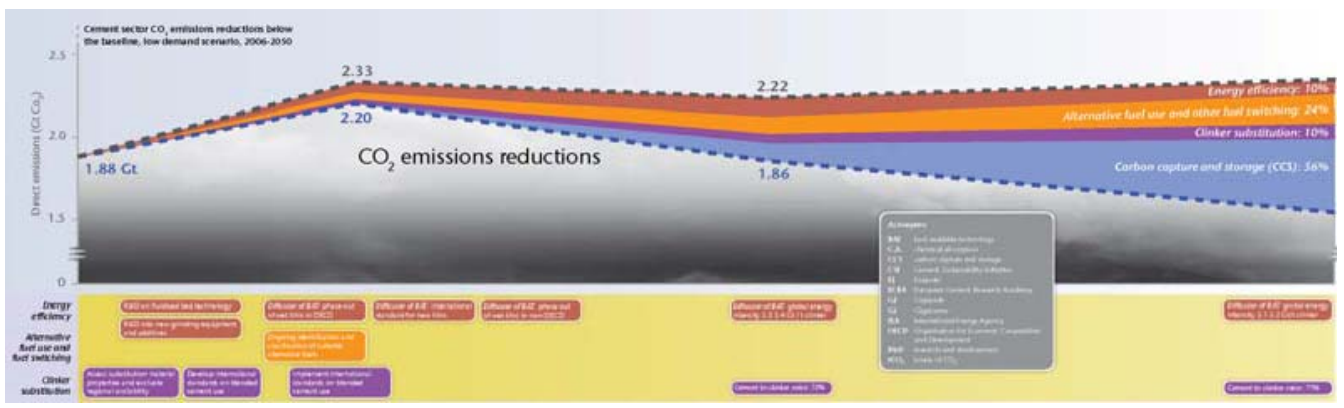

Fig. 14. Cement industry roadmap targets (Source: CSI)

In this situation, in the reduction of $\mathrm{CO}_{2}$ emissions in cement industry has attracted a large number of researchers. Bosoaga et al. (2009) summarize the different CO2 capture technologies suitable for cement industry and assesses the potential of the calcium looping cycle as a new route for $\mathrm{CO}_{2}$ capture in the cement industry. Rehan and Nehdi (2005) discuss the policy implications of carbon dioxide emissions and climate change in the cement industry. Anand et al. (2006) apply a system dynamics approach to assessment and mitigation of $\mathrm{CO}_{2}$ emissions from the cement industry in India, and a $42 \%$ reduction in the $\mathrm{CO}_{2}$ emissions can be achieved in the year 2020 based on integrated mitigation scenarios which incorporate energy conservation and structural management in cement manufacturing processes. Szabo et al. (2006) present the foreseeable technological evolution of the cement industry under business as usual circumstances, and examines the effects on the sector of carbon trading. Worrell et al. (2001) review the total $\mathrm{CO}_{2}$ emission from cement making (including process and energy-related emissions) and discuss $\mathrm{CO}_{2}$ emission mitigation options. Hao et al. (2011) present five low-carbon measures and implementation approach to Chinese cement industry: Increasing industrial concentration degree and developing new dry 
process cement, Processing waste in cement kilns and reducing the use of raw materials and fuels, Increasing the amount of admixture in cement, Producing cement from calcium oxide content solid waste, Taking energy-saving measures such as co-generation and grinding technology.

In future, the stakeholders of cement industry should become more familiar with reduction of $\mathrm{CO}_{2}$ emissions and associated climate change issues, along with emerging environmental policies that may affect of this industry.

\subsubsection{Transportation Engineering}

Since 1990, transportation sector emissions have grown more in absolute terms than any other sector (Cambridge Systematics, Inc.). World Energy Council has pointed out that transportation engineering impacts on the environment significantly, accounting for between $20 \%$ and $25 \%$ of world energy consumption and carbon dioxide emissions (World Energy Council).

In this case, carbon dioxide emissions from transportation engineering have been attracted by a large number of scholars. For instance, Lu et al. (2007) adopt the Division index approach to explore the impacts of five factors on the total carbon dioxide emissions from highway vehicles in Germany, Japan, South Korea and Taiwan during 1990--2002. From the results in this study, they find out that the rapid growths of economy and vehicle ownership are the most important factors for the increased $\mathrm{CO}_{2}$ emissions, whereas population intensity contributes significantly to emission decrease. Liao et al. (2009) examine carbon dioxide emissions of truck-only transportation using activity-based emission modeling and compare those with intermodal coastal shipping and truck movements, and summarize that replacing long-haul truck transport with the intermodal can significantly reduce carbon dioxide emission significantly because of the efficiency of maritime fuel. Lin (2010) focuses on five national parks in Taiwan and applies a bottom-up approach to determine the amount of $\mathrm{CO}_{2}$ emissions from domestic tourism transport in 1999-2006. The scenario analysis indicates that $\mathrm{CO}_{2}$ emission can be reduced by increasing load factors of transport, tourist switching from private cars to public transport and going to destinations close to their points of departure, which can be achieved by authorities through activity management, regulation control and price adjustment.

Consequently, engineering management for transportation is necessary. The transportation community is being challenged to develop management approach and strategies to reduce $\mathrm{CO}_{2}$ emissions. Cambridge Systematic point out that pricing and other forms of travel demand management are important tools in reducing $\mathrm{CO}_{2}$ emission and addressing fuel consumption. By life cycle assessment (LCA) approach, Kuo and Chen (2009) explore the environmental impacts of island tourism. This research summarize that per tourist per trip emits $109,034 \mathrm{~g}$ of $\mathrm{CO}_{2}$ and the transportation consumes the largest energy (67\%); in particular, the airplane sector. Paravantis and Georgakellos (2007) develop aggregate car ownership and bus fleet models in order to forecast and compare fuel consumption and $\mathrm{CO}_{2}$ emissions from passenger cars and buses, and predict that the contribution of cars to total $\mathrm{CO}_{2}$ emissions will rise to an astounding $95 \%$ of total $\mathrm{CO}_{2}$ emissions from road passenger 
transport (excluding taxis and mopeds). Lu et al. (2007) propose that sustainable transport policy in Taiwan should focus on

improving the operation and energy use of its highway transportation system by implementing an intelligent transportation system (ITS) with demand management, constructing an integrated feeder system, and encouraging the use of green transport modes.

\subsection{Research Methods}

In this study, there are six articles associated with the DICE model. Dynamic Integrated Model of Climate and the Economy (DICE) are initialized by Nordhaus in 1992. It is an integrate model that incorporates both the dynamics of emissions and impacts and the economic costs of policies to curb emissions (Nordhaus, 1992). DICE model contains both the traditional economic sector and novel climate sector. The economic costs control must be considered in all engineering projects, so DICE model can be used in engineering management on the basis of the reduction of carbon dioxide emissions constraints. Popp used the advanced model in Popp (2004), named ENTICE model, which consider endogenous technological change in the DICE model of global warming. Technological change that enhances energy efficiency is stimulated by changes in the price energy, including carbon taxes.

Inexact Dynamic Optimization Model is first proposed by Huang and has been applied to practical engineering projects, such as agricultural/timbering activities in Mackenzie Basin, Canada (Huang et al, 1996), energy system management and GHGemission control in the Municipality of Beijing (Lin and Huang, 2009), greenhouse-gas emission management and sustainable renewable energy development under uncertainty (Lin and Huang, 2009), municipal solid waste (MSW) management under uncertainty (Lu et al., 2009).

System Dynamics Approach is also effective to reduce emissions of carbon dioxide in engineering projects. It is very important to sustainable development as a decision making tool. Chen et al. (2005) develop a dynamic strategy planning theory and system to generate the land use plans of the Nankan river basin in Taoyuan County of Chinese Taiwan. Shi and Gill (2005), Fong (2009) use systems dynamics model to develop effective policies for the sustainable development of ecological agriculture in China and plan urban process toward stabilizing carbon dioxide emissions from cities in Malaysia, respectively. Anand et al. (2006) employ system dynamics model to estimate $\mathrm{CO}_{2}$ emissions from the cement industry in India. Shen et al. (2009) also apply the system dynamics model for the sustainable land use and urban development in Hong Kong. From the five articles mentioned above, we can see that system dynamics model occupies most of the proportion of System Dynamics Approach, so it should be given more attention in subsequent research.

There are seven articles associated with the Integrated Approach, and they account for $22 \%$ in all 32 articles. Bernow et al. (1998) discuss and evaluate the policies to reduce carbon dioxide $\left(\mathrm{CO}_{2}\right)$ emissions from electricity generation in the US using an integrated approach. Rao (2001) develop integrated approach for sustainable development of land and water sources, and concluded that for sustainable development, a holistic and systematic approach is essential that takes into account analysis of multiple objectives, 
impact and risk analysis apart from decision-making at the grassroots level. Lis (2006) consider uncertainties associated with the future performance of buildings due to changes in regional and local-scale climatic impact, and proposed an integrated approach to risk management of future climate change impacts in the construction industry. Goderniaux et al. (2007) use an integrated approach to assess climate change impacts on a regional chalky aquifer in Belgium. Rustad (2008) develop an integrated hydrological model in order to study the potential effects of climate change on groundwater resources. Pataki (2009) use an integrated approach to improving fossil fuel emissions scenarios with urban ecosystem studies. Richter and Hamacher (2002) built an integrated model for energy and environment management in Augsburg, Germany.

Besides, Pyke et al. (2007) propose a decision assessment and decision inventory that will provide systematic information describing the relevant attributes of climate-related decisions. Application of this approach will help provide more effective decision support based on a balanced foundation of analytical tools, environmental data, and relevant information about decisions and decision makers. Kueppers et al. (2004) develop a policy tool, in the form of a multi-attribute decision matrix, which can be used to evaluate potential and completed land-use projects

for their climate, environmental and socioeconomic impacts simultaneously. Kambo et al. (1991) present a municipal energy systems planning model for the City of Delhi in India, and $\mathrm{Li}$ et al. (2004) also propose a municipal energy systems planning model for the City of Hohhot, China. Lowe and Lorenzoni (2007) report on 22

'expert' interpretations elicited through a mental models approach, and encapsulated in a 'meta'-influence diagram, denoting three conceptualizations of danger in relation to climate change. Haurie (2001) present a MARKAL-LITE model for municipal energy systems planning in Geneva. Vallega (1996) and Nordrum et al. (2004) use a consistent approach to using structure within the coastal system and estimating greenhouse gas emissions for the petroleum industry. Mongelli et al. (2006) use InputOutput model to calculate the intensities of energy consumption and the related Green House Gases emission, for each Italian economic sector. Kaewniyompanit et al. (2006) conduct a modeling study that focused on power supply variations in Japan. Litynski et al. (2006) use collaborative approach to carbon management in The United States Department of Energy's Regional Carbon Sequestration Partnerships program. Cai et al. (2008) report an energy systems (EIA,

2001) planning model for GHG-emission management and climate-change impact analysis in the Region of

Kitchener-Waterloo, Canada.

\section{The Trend and Future Perspective}

This review has raised three questions that deserved further research. First, we know that Energy Engineering, Iron and Steel Industry, Cement Industry, and Transportation Engineering must be given a special attention in the reduction of carbon dioxide emissions for the goal of sustainable development. Secondly, there are 13 approaches used in the 175 empirical studies. Among them, the most widely used methods are Dynamic Integrated Model Climate and the Economy (DICE), Inexact 
Dynamic Optimization Model, System Dynamics Approach, and Integrated Approach. Thirdly, the consideration of carbon dioxide emissions as the constraint is necessary in the engineering project and industry engineering, and some key mitigation technologies and practices, measures, instruments and policies of engineering management are shown to be environmentally effective to the reduction of carbon dioxide emissions.

Besides, the following engineering fields deserve special attention in the future: NonEnergy Use of Fuels, Natural Gas Systems, Municipal Solid Waste Combustion, Lime Manufacture, Ammonia Production and Urea Consumption, Limestone and Dolomite Use, Cropland Remaining Cropland, Soda Ash Manufacture and Consumption, and so on. On the other hand, highly advanced mitigation technologies, which probably be effective to the reduction of carbon dioxide emissions in engineering project and industry engineering in the future, are listed as follows: carbon dioxide capture and storage (CCS) for gas, biomass and coal-fired electricity generating facilities; advanced nuclear power; advanced renewable energy, including tidal and wave energy, concentrating solar, and solar photovoltaic; second generation bio-fuels; higher efficiency aircraft; advanced electric and hybrid vehicles with more powerful and reliable batteries; integrated design of commercial buildings including technologies, such as intelligent meters that provide feedback and control; solar photovoltaic integrated in buildings; CCS for cement, ammonia, and iron manufacture; inert electrodes for aluminum manufacture; improvements of crop yields; tree species improvement to increase biomass productivity and carbon sequestration.

In addition, with in-depth research of engineering management and a great concern over climate change, more and more fields of engineering management will be permeated with the reduction of carbon dioxide emissions as constraints. Therefore, for a period of time in the future, low carbon modes (Kramer and Haigh, 2009) and low carbon technologies (Galiana and Green, 2009) focus in many engineering project and industry engineering to reduce carbon dioxide emissions. As a result, Low Carbon Engineering Management may also be a research hotspot in the future.

Based on our findings above, we can conclude that effective and sustainable engineering management shall dedicate more effects in the reduction of carbon dioxide emission. Only through this way can we find opportunities to realize sustainable development.

\section{Conclusions}

In this paper, we present a systematic review that identifies the empirical studies of engineering management based on the reduction of carbon dioxide emissions constraints. After extensive literature review, we summarize past research contents and approaches and point out the future perspective of engineering management based on the reduction of carbon dioxide emissions constraints.

Our study fulfills the following three aims: (1) Share the results of our investigations on engineering management based on the reduction of carbon dioxide emissions constraints. Our experiences of attempting systematic literature reviews have confirmed that the basic steps in the systematic review process appear as relevant to reduction of carbon dioxide emissions as they do in engineering 
management. We particularly note that the reporting of empirical studies in reduction of carbon dioxide emissions has a number of shortcomings. The lack of conformity in searching facilities, across commonly used digital libraries is also a hindrance to conduct systematic literature reviewers. (2) Identify (a) Which engineering project or industry engineering requiring special attentions in the reduction of carbon dioxide emissions constraints for the goal of sustainable development? (b) What research methods have been used in engineering management on the basis of the reduction of carbon dioxide emissions constraints? (c) Which key mitigation technologies and practices, measures, instruments and policies of engineering management are shown to be environmentally effective to the reduction of carbon dioxide emissions? (3) Point out the trend and future perspective. To achieve the ultimate objective of the convention to stabilize greenhouse gas concentration in the atmosphere at a level that would prevent dangerous anthropogenic interference with the climate system, we shall recognize the scientific view that the increase in global temperature should be below 2 degrees, on the basis of equity and in the context of sustainable development, enhance our long-term cooperative action to combat climate change. To sum up, for realizing sustainable development, we must consider the reduction of carbon dioxide emissions as necessary condition in engineering management. Only in this way, we will be able to improve the harsh environment and achieve the economic objectives of sustainable development.

This review will be useful for policymakers and engineering management analysts alike. Besides, it will be essential to worldwide engineering management and to the mitigation of climate change.

Acknowledgement. This research was sponsored by Natural Science Foundation of China (NSFC Grant no. 71401075), Jiangsu Provincial Natural Science Foundation of China (Grant no. BK20130753), and the Fundamental Research Funds for the Central Universities (Grant No. 30916013105).). We would like to extend our appreciation to all the reviewers and editors who contributed to this research.

\section{References}

International Energy Agency (IEA), On line at: www.iea.org.

World Business Council for Sustainable Development: Cement Sustainability Initiative (CSI), On line at: http://www.wbcsdcement.org.

American Society for Engineering Management (ASEM), On line at: http://www.asem.org. Editorial (2010), Climate of suspicion, Nature, 463, 269.

Editorial (2009), After Copenhagen, Nature, 462, 957-958.

Ministry of Environment and Water Resources, On line at: http://app.mewr.gov.sg/. Cambridge Systematics, On line at: http://www.camsys.com/kb $\backslash$ hotissue $\backslash$ climate.htm. American Institute of Chemical Engineers, On line at: http://www.aiche.org/ESCarbonMgmt. The Guardian, On line at: http://www.guardian.co.uk/.

UNDP (2007), Human development report 2007/2008, fighting climate change: human solidarity in a divided world. New York: United Nations Development Program.

Goddard Institute for Space Studies, On line at: http://data.giss.nasa.gov/gistemp/. Transport Technologies and Policy Scenarios, World Energy Council, 2007. Scripps Institution of Oceanography, On line at: http://scripps.ucsd.edu/. International Panel on Climate Change (IPCC), On line at: http://www.ipcc.ch/. 
Low Carbon in Singapore, On line at: http://www.lowcarbonsg.com/2009/05/14/singapores-carbondioxide-emissions-per-capita-and-carbon-intensity/.

Anand S., Vrat P., Dahiya R., (2006), Application of a system dynamics approach for assessment and mitigation of $\mathrm{CO}_{2}$ emissions from the cement industry, Journal of Envinnmental Management, 79, 383-398.

Amon B., Kryvoruchko V., Amon T., (2006), Influence of different methods of covering slurry stores on greenhouse gas and ammonia emissions. in: International Congress Series Greenhouse Gases and Animal Agriculture: An Update, Proceedings of the 2nd International Conference on Greenhouse Gases and Animal Agriculture, Switzerland, pp. 315-318.

Amon B. and Kryvoruchko V., (2006), Greenhouse gas and ammonia emission abatement by slurry treatment. in: International Congress Series Greenhouse Gases and Animal Agriculture: An Update. Proceedings of the 2nd International Conference on Greenhouse Gases and Animal Agriculture, Switzerland, pp. 295-298.

Bernow S., Dougherty W., and et al., (1998), An integrated approach to climate policy in the US electric power sector, Energy Policy,26, 375-393.

Blanco C, Lasheras J, et al., (2008), A systematic review and comparison of security ontologism, The Third International Conference on Availability, Reliability and Security, pp. 813-820.

Bogner J., Pipatti R., et al., (2008), Mitigation of global greenhouse gas emissions from waste: Conclusions and strategies from the Intergovernmental Panel on Climate Change (IPCC) Fourth Assessment Report, Waste Management and Researh, 26, 11-32. Bosoaga A., Masek O., Oakey J., (2009), CO2 Capture Technologies for Cement Industry, Proceedings of the 9th International Conference on Greenhouse Gas Control Technologies (GHGT-9), Washington DC, USA, pp. 133-140.

Bouwman A., (1990), Land use related sources of greenhouse gases: Present emissions and possible future trends, Land Use Policy, 7, 154-164.

Brereton P., Kitchenham B., (2007), Lessons from applying the systematic literature review process within the software engineering domain, The Journal of Systems and Software, 80, 571-583.

Buchanan A., Honey B., (1994), Energy and carbon dioxide implications of building construction, Energy and Buildings, 20, 205-217.

Buchanan A., Levine S., (1999), Wood-based building materials and atmospheric carbon emissions, Environmental Science \& Policy, 2, 427-437.

Cai Y., Huang G., et al., (2008), Development of an optimization model for energy systems planning in the Region of Waterloo, International Journal of Eneryy Researh, 32, 988-1005.

Cagiao J., Gomez B., and et al., (2011), Calculation of the corporate carbon footprint of the cement industry by the application of MC3 methodology, Ecological Indicators, 11, 1526-1540.

Cairns M. and Meganck R., (1994), Carbon sequestration, biological diversity, and sustainable development: Integrated forest management, Environmental Management, 18, 13-22.

Chen C., Liu W., et al., (2005), Development of a dynamic strategy planning theory and system for sustainable river basin land use management, Science of The Total Envinonment, 346, 17-37.

Chen C., Liu W., et al., (2010), A two-stage inexact-stochastic programming model for planning carbon dioxide emission trading under uncertainty, Applied Energy, 87, 1033-1047.

Cherubini F., Stromman A., Hertwich E., (2011), Effects of boreal forest management practices on the climate impact of $\mathrm{CO}_{2}$ emissions from bioenergy, Ecological Modelling, Inpress.

Christensen T., Gentil E., and et al., (2009), C balance, carbon dioxide emissions and global warming potentials in LCA-modelling of waste management systems, Waste Management and Researh, 27, 707715.

Christensen T., Simion F., and et al. (2009), Global warming factors modeled for 40 generic municipal waste management scenarios, Waste Management and Researh, 27, 871-884.

Cline W., (1992), The Economics of Global Warming. Institute for International Economics, Washington, DC.

Creutzig F., He D., (2009), Climate change mitigation and co-benefits of feasible transport demand policies in Beijing, Transportation Researh Part D: Transport and Environment, 14, 120-131.

Davis A., Dieste O., and et al., (2006), Effectiveness of Requirements Elicitation Techniques: Empirical Results Derived from a Systematic Review, 14th IEEE International Requirements Engineering Conference. 
Dyba T., Dingsoyr T., Hanssen G., (2007), Applying systematic reviews to diverse study types: an experience report, Proceedings of the ESEM, Madrid, pp. 225-234.

Dyer J., Desjardins R., (2003), Simulated Farm Fieldwork, Energy Consumption and Related Greenhouse Gas Emissions in Canada, Biosystems Engineering, 85, 503-513.

Eisted R., Larsen A., Christensen T., (2009), Collection, transfer and transport of waste: Accounting of greenhouse gases and global warming contribution, Waste Management and Research, 27,, 738-745.

Fisher B., Nakicenovic N., and et al., (2007), Issues related to mitigation in the long term context. Climate Change 2007: Mitigation, Cambridge University Press, Cambridge.

Freibauer A., (2003), Regionalised inventory of biogenic greenhouse gas emissions from European agriculture, European Journal of Agronomy, 19, 135-160.

Follett R., Shafer S., and et al., (2005), Research and implementation needs to mitigate greenhouse gas emissions from agriculture in the USA, Soil and Tillage Research Greenhouse Gas Contributions and Mitigation Potential in Agricultural Regions of North America, 83(1), 159-166.

Fong W., Matsumoto H., Lun Y., (2009), Application of System Dynamics model as decision making tool in urban planning process toward stabilizing carbon dioxide emissions from cities, Building and Envinonment, 44, 1528-1537.

Galiana I. and Green C., (2009), Let the global technology race begin, Nature, 462, 570-571.

Gao H. and Stasko T., (2009), Diversification in the driveway: mean-variance optimization for greenhouse gas emissions reduction from the next generation of vehicles, Energy Policy, 37, 5019-5027.

Gentil E., Christensen T., Aoustin E., (2009), Greenhouse gas accounting and waste management, Waste Management and Research, 27, 696-706.

Gentil E., Clavreul J., Christensen T., (2009), Global warming factor of municipal solid waste management in Europe, Waste Management and Research, 27, 850-860.

Gielen D. and Moriguchi Y., (2002), $\mathrm{CO}_{2}$ in the iron and steel industry: an analysis of Japanese emission reduction potentials, Energy Policy, 30, 849-863.

Goderniaux P., Brouyere S., Dassargues, A., (2007), Integrated approach for assessing climate change impacts on a regional chalky aquifer in Belgium, Building Research and Information, Perugia, Italy: IAHS Press.

Gustavsson L., Joelsson A., Sathre R., (2010), Life cycle primary energy use and carbon emission of an eightstorey wood-framed apartment building, Energy and Buildings, 42, 230-242.

Hannay J. and Sjoberg D., (2007), A Systematic Review of Theory Use in Software Engineering Experiments, IEEE Tansactions on software engineering, 33, 87-107.

Hatzigeorgiou E., Polatidis H. and Haralambopoulos D., (2010), Energy CO2 Emissions for 1990-2020: A Decomposition Analysis for EU-25 and Greece, Energy Sources, Part A, 32, 1908-1917.

Hao L., Zhao F. and Zhao P., (2011), Measures to reduce carbon dioxide emission of China cement industry. 2011 International Conference on Chemical Engineering and Advanced Materials, Changsha, China, 233-235.

Hayes S., Hower J., Scott M., (2003), Profit from effective greenhouse gas management- A sixstep plan, Environmental Management, 99, 36--43.

Haurie A., (1991), MARKAL-LITE: An energy/environment model to assess urban sustainable development policies, On line at: http://ecolu-info.unige.ch/recherche/su-/tra/contributions/mark-al-lite $\backslash 02$.pdf.

Hidalgo I., Szabo L., et al., (2005), Technological prospects and $\mathrm{CO}_{2}$ emission trading analyses in the iron and steel industry: A global model, Energy, 30, 583-610.

Horvath A. and Pewsner D., (2004), Systematic reviews in laboratory medicine: principles, processes and practical considerations, Clinica Cbimica Acta, 342, 23-39.

Huang G., Cohen S., and et al., (1996), Incorporation of Inexact Dynamic Optimization with Fuzzy Relation Analysis for Integrated Climate Change Impact Study, Journal of Environmental Management, $48,, 45-68$.

Hunt J., (2007), Climate change and civil engineering challenges. Proceedings of the Institution of Civil Engineers: Civil Engineering,pp. 170-175.

Humphreys K., Mahasenan M., (2002), Towards a sustainable cement industry: climate change, On line at: http://www.wbcsdcement.org/pdf/final\_report8.pdf, accessed on 12 January 2003.

Ismail R., (1995), An economic evaluation of carbon emission and carbon sequestration for the forestry sector in Malaysia, Biomass and Bioenery, 8, 281-292. 
Jha A., Sharma C., and et al., (2008), Greenhouse gas emissions from municipal solid waste management in Indian mega-cities: A case study of Chennai landfill sites, Chemosphere, 71, 750-758.

Kaewniyompanit S., Sugihar, H., Tsuj, K., (2006), A model for urban energy system design in consideration of electric load variation in a specific area due to PV system installation. Proceeding of Enerny and Power Systems, Chiang Mai, Thailand.

Kambo N., Handa B., Bose R., (1991), Linear goal programming model for urban energy-economyenvironm-ent interaction, Energy Build, 16, 537-551.

Kato Y., Obara T., and et al., (2011), Performance analysis of active carbon recycling energy system, Progress in Nuclear Energy, 53,1017-1021.

Kato Y., Liu C., et al., (2005), Carbon dioxide zero-emission hydrogen system based on nuclear power, Progress in Nuclear Energy, 47, 504-511.

Kato,Y., Otsuka K., Liu C., (2005), Carbon Dioxide Zero-Emission Hydrogen Carrier System for Fuel Cell Vehicle, Chemical Engineering Researh and Design, 83, 900-904.

Khan K., (2005), Systematic reviews of diagnostic tests: a guide to methods and application, Best Practice \& Research Clinical Obstetrics and Gynaecology, 19, 37-46.

Kinsman J., Kaster G., and et al., (2000), Forest carbon management, the greenhouse effect and electric utilities, Environmental Science \& Technology, 3, 115-122.

Kirschen M., Risonarta V., Pfeifer H., (2009), Energy efficiency and the influence of gas burners to the energy related carbon dioxide emissions of electric arc furnaces in steel industry, Energy, 34, 10651072.

Kitchenham B., (2004), Procedures for performing systematic reviews. Technical Report, 1-28. Keele University.

Kitchenham B., Mendes E., and et al., (2006), A systematic review of cross vs. within-company cost estimation studies, EASE 2006 10th International Conference on Evaluation and Assessment in Software Engineering, UK, 89-98. Kramer G., Haigh M., (2009), No quick switch to low-carbon energy. Nature, 462, 568-569.

Kueppers L., Baer P., and et al., (2004), A decision matrix approach to evaluating the impacts of land-use activities undertaken to mitigate climate change: An editorial essay, Climatic Change, 63, 247-257.

Kulshreshtha S., Junkins B., Desjardins R., (2000), Prioritizing greenhouse gas emission mitigation measures for agriculture, Agricultural Systems, 66, 145--166.

Kuo N., Chen P., (2009), Quantifying energy use, carbon dioxide emission, and other environmental loads from island tourism based on a life cycle assessment approach, Journal of Cleaner Production, 17, $1324-1330$.

Larson E., (2006), A review of life-cycle analysis studies on liquid biofuel systems for the transport sector, Energy for Sustainable Development, 10, 109-126.

Larsen A., Merrild H., Christensen T., (2009), Recycling of glass: Accounting of greenhouse gases and global warming contributions, Waste Management and Research, 27, 754-762.

Lempert R., Sanstad A., Schlesinger M., (2004), Multiple Equilibrium in a Stochastic Implementation of DICE with Abrupt Climate Change, Energy Economics, 5-6, 677-689.

Levine M., Price L., Martin N., (1996), Mitigation options for carbon dioxide emissions from buildings, Energy Policy, 24, 937-949. Li C, Suding P., et al., (2004), A study on integrated programming model of urban energy supplying based on sustainable development, International Journal of Global Energy, 22, 99-118.

Liao C., Lu C., Tseng P., (2011), Carbon dioxide emissions and inland container transport in Taiwan, Journal of Transport Geography, 19, 722-728.

Liao C., Tseng P., Lu C., (2009), Comparing carbon dioxide emissions of trucking and intermodal container transport in Taiwan, Transportation Researh Part D: Transport and Environment, 14, 493-496.

Lin Q. and Huang G., (2009), Planning of energy system management and GHG-emission control in the Municipality of Beijing- An inexact-dynamic stochastic programming model. Energy Policy, 37, 4463-4473.

Lin Q. and Huang G., (2009), A dynamic inexact energy systems planning model for supporting greenhouse-gas emission management and sustainable renewable energy development under uncertainty- A case study for the City of Waterloo, Canada, Renewable and Sustainable Enengy Reviens, 13, 1836-1853. 
Lin T., (2010), Carbon dioxide emissions from transport in Taiwan's national parks, Tourism Management, 31, 285-290.

Lin J., Wu C., and et al., (2012), Behavioral intentions toward a forestation and carbon reduction by the Taiwanese public, Forest Policy and Economics, 14, 119-126.

Lis K., (2006), Integrated approach to risk management of future climate change impacts, Building Research and Information, 34, 1-10.

Litynski J., Klara S., and et al., (2006), The United States Department of Energy's Regional Carbon Sequestration Partnerships program: A collaborative approach to carbon management, Envinonment International, 32, 128-144.

Liu D., Li N., and et al., (2011), Study on energy strategy of Chinese capital region under the new national policy of reducing carbon dioxide emissions, Procedia Environmental Sciences, 5, 2-11.

Lowe T., Lorenzoni I., (2007), Danger is all around: Eliciting expert perceptions for managing climate change through a mental models approach, Global Environmental Change, 17, 131-146.

Lu I., Lin S., Lewis C., (2007), Decomposition and decoupling effects of carbon dioxide emission from highway transportation in Taiwan, Germany, Japan and South Korea, Energy Policy, 35, 3226-3235.

Lu H., Huang G., and et al., (2009), An inexact dynamic optimization model for municipal solid waste management in association with greenhouse gas emission control, Journal of Environmental Management, 90, 396-409.

Maraseni T., Maroulis J., (2008), Piggery, From environmental pollution to a climate change solution, Journal of Environmental Science and Health-Part B Pesticides, Food Contaminants, and Agricultural Wastes, 43, 358-363.

Mayor K., Tol R., (2010), Scenarios of carbon dioxide emissions from aviation, Global Environmental Change, 20, 65-73.

Merrild H., Christensen T., (2009), Recycling of wood for particle board production: Accounting of greenhouse gases and global warming contributions, Waste Management and Researh, 27(8), 781-788.

Mohareb A., Warith M., Diaz R., (2008), Modelling greenhouse gas emissions for municipal solid waste management strategies in Ottawa, Ontario, Canada, Resources, Conservation and Recycling, 52, 1241 1251.

Morita T., Matsuoka Y., Kainuma M., (1995). Carbon dioxide emission scenarios and nuclear energy, Progress in Nuclear Energy, 29, 143-150.

Mongelli I., Tassielli G., Notarnicola B., (2006), Global warming agreements, international trade and energy/carbon embodiments: an input-output approach to the Italian case, Energy Policy, 34, 88-100.

Mpelasoka F., Hennessy K., and et al., (2008), Comparison of suitable drought indices for climate change impacts assessment over Australia towards resource management, International Journal of Climatology, 28, 1283-1292.

Mroueh U., Ajanko-Laurikko S., and et al., (2007), New waste management concepts in the reduction of greenhouse gas emissions. VTT Tiedotteita- Valtion Teknillinen Tutkimuskeskus.

Mulrow C., Cook D., (1998), Systematic Reviews: Synthesis of Best Evidence for Health Care Decisions. Philadelphia: Am. College of Physicians.

Nakata T., Lamont A., (2000), Analysis of the impacts of carbon taxes on energy systems in Japan, Energy Policy, 29, 159-166. Nicolas J., Toval A., (2009), On the generation of requirements specifications from software engineering models: A systematic literature review, Information and Software Technology, 51, 1291-1307.

Nordhaus W., (1992), The DICE Model: Background and Structure of a Dynamic Integrated Climate-Economy Model of the Economics of Global Warming, On line at: http://cowles.econ.yale.edu/P/cd/d10a/d1009.pdf.

Nordhaus W., (1993), Rolling the DICE: An Optimal Transition Path for Controlling Greenhouse Gases, Resoure and Eneryy Economics, 15, 27-50.

Nordhaus W. and Boyer J., (2000), Warming the World Economic Models of Global Warming. The MIT Press, Cambridge.

Nordrum S., Loreti C., and et al., (2004), Developing a consistent approach to estimating greenhouse gas emissions for the petroleum industry, Industry and Environment, 27, 72-75.

Oliver M., (2007). Is This What It Takes to Save the World? Nature, 447, 132-136.

Ou X., Zhang X., Chang S., (2010), Scenario analysis on alternative fuel/vehicle for China's future road transport: Life-cycle energy demand and GHG emissions, Energy Policy, 38, 3943-3956. 
Ou X., Yan X., Zhang X., (2011), Life-cycle energy consumption and greenhouse gas emissions for electricity generation and supply in China, Applied Energy, 88, 289-297.

Paravantis J., Georgakellos D., (2007), Trends in energy consumption and carbon dioxide emissions of passenger cars and buses, Technological Forecasting and Social Change, 74, 682-707.

Pataki D., Emmi P., et al., (2009), An integrated approach to improving fossil fuel emissions scenarios with urban ecosystem studies, Ecological Complexity, 6, 1-14.

Pickin J., Yuen S., Hennings H., (2002), Waste management options to reduce greenhouse gas emissions from paper in Australia, Atmospheric Environment, 36, 741-752.

Pipatti R., Savolainen I., (1995), Role of energy production in the control of greenhouse gas emissions from waste management, Energy Conversion and Management, 37, 1105-1110.

Popp D., (2004), ENTICE: endogenous technological change in the DICE model of global warming, Journal of Environmental Economics and Management, 48, 742-768.

Pruess K., (2006), Enhanced geothermal systems (EGS) using $\mathrm{CO}_{2}$ as working fluid- A novel approach for generating renewable energy with simultaneous sequestration of carbon, Geothermics, 35, 351367.

Pyke C., Bierwagen B., and et al., (2007), A decision inventory approach for improving decision support for climate change impact assessment and adaptation, Environmental Science \& Policy, 10, 610-621.

Rao D., (2001), A remote sensing-based integrated approach for sustainable development of land water resources, IEEE Transactions on Systems, Man and Cybernetics Part C: Applications and Reviews, 31, 207215.

Rehan R., Nehdi M., (2005), Carbon dioxide emissions and climate change: policy implications for the cement industry, Environmental Science \& Policy, 8, 105-114.

Ren L., Wang W., (2011), Analysis of Existing Problems and Carbon Emission Reduction in Shandong's Iron and Steel Industry, Energy Procedia, 5, 1636-1641.

Richter S., Hamacher T., (2002), URBS-An integral model for investigations on future urban energy systems, On line at: http://www.richter-info.de/files/Paper \Power-/Gen $\backslash 2003 \backslash$ Richter.pdf.

Riedy C., Diesendorf M., (2003), Financial subsidies to the Australian fossil fuel industry, Energy Policy, 31, 125-137.

Rustad L., (2008), The response of terrestrial ecosystems to global climate change: Towards an integrated approach, Science of the Total Environment, 404, 222-235.

Sampson M., Shojania K., and et al., (2008), Systematic reviews can be produced and published faster, Journal of Clinical Epidemiology, 61, 531-536.

Scheutz C., Kjeldsen P., Gentil E., (2009), Greenhouse gases, radioactive forcing, global warming potential and waste management- An introduction, Waste Management and Research, 27, 716-723.

Sheinbaum C., Ozawa L., Castillo D., (2009), Using logarithmic mean Division index to analyze changes in energy use and carbon dioxide emissions in Mexico's iron and steel industry, Energy Economics, 32, 1337-1344.

Shen Q., Chen Q., and et al., (2009), A system dynamics model for the sustainable land use planning and development, Habitat International, 33, 15-25.

Shi T., Gill R., (2005), Developing effective policies for the sustainable development of ecological agriculture in China: the case study of Jinshan County with a systems dynamics model, Ecological Economics, 53, 223-246.

Si M., Thompson S., Calder K., (2011), Energy efficiency assessment by process heating assessment and survey tool (PHAST) and feasibility analysis of waste heat recovery in the reheat furnace at a steel company, Renewable and Sustainable Energy Reviens, 15, 2904-2908.

Sinyak Y., Nagano K., (1994), Global energy strategies to control future carbon dioxide emissions, Energy, 19, 227-2368.

Snyder C., Bruulsema T., and et al., (2009), Review of greenhouse gas emissions from crop production systems and fertilizer

management effects, Ecosystems \& Environment, 133, 247-266.

Skutsch M., Bird N., and et al., (2007), Clearing the way for reducing emissions from tropical deforestation, Environmental Science \& Policy, 10, 322-334.

Stewart S., (2004), Method for Reporting in- Use Vehicle Fuel Consumption and Carbon Dioxide Emissions from a Fast-Pass

Transient Inspection, Journal of the Air and Waste Management Association, 54, 593-599. 
Sun W., Cai J., and et al., (2011), Change in Carbon Dioxide (CO2) Emissions From Energy Use in China's Iron and Steel Industry,

International Journal of Iron and Steel Researh, 18, 31-36.

Suzuki M., Oka T., Okada K., (1995), The estimation of energy consumption and $\mathrm{CO}_{2}$ emission due to housing construction in Japan,

Energy and Buildings, 22, 165-169.

Szabo L., Hidalgo I., and et al., (2006), $\mathrm{CO}_{2}$ emission trading within the European Union and Annex B countries: The cement industry case, Energy Policy, 34, 72-87.

Thompson S., Sawye, J., et al., (2008), Modeling landfill gas generation to determine targets and strategies to reduce greenhouse gases from landfills, Journal of Solid Waste Technology and Management, $34,27-34$.

Timilsina G., Csordas, S., Mevel S., (2011), When does a carbon tax on fossil fuels stimulate biofuels? Ecological Economics, 70, 2400-2415.

Tokushige K., Akimoto K., (2011), Role and issues of CCS in long-term sustainable emission reductions and toward sustainable development, Energy Procedia, 4, 5889-5894.

Tricco A., Tetzlaff J., and et al., (2008), Few systematic reviews exist documenting the extent of bias: a systematic review, Journal of

Clinical Epidemiology, 61, 422-434.

Tsoutsos T., Papadopoulou, E., and et al., (2008), Supporting schemes for renewable energy sources and their impact on reducing the emissions of greenhouse gases in Greece, Renewable and Sustainable Energy Reviews, 12, 1767-1788.

Utamura M., (2005), Analytical model of carbon dioxide emission with energy payback effect, Energy, 30, 2073-2088.

Vallega A., (1996), The coastal use structure within the coastal system: A sustainable developmentconsistent approach, Journal of Marine Systems, 7, 95-115.

Walsh C., Jakeman P., et al., (2008), A comparison of carbon dioxide emissions associated with motorized transport modes and cycling in Ireland, Transportation Researh Part D: Transport and Environment, 13, 392-399.

Wang K., Wang C., et al., (2007), Scenario analysis on $\mathrm{CO}_{2}$ emissions reduction potential in China's iron and steel industry, Energy Policy, 35, 2320-2335.

Wiel S., Martin N., et al., (1998), The role of building energy efficiency in managing atmospheric carbon dioxide, Environmental Science \& Policy, 1, 27-38.

Worrell E., Price L., et al., (2001), Carbon dioxide emissions from the global cement industry, Annual Review of Energy and the Environment, 26, 303-329.

Worrell E., Price L., et al., (2001), Energy efficiency and carbon dioxide emissions reduction opportunities in the US iron and steel sector, Energy, 26(5), 513-536.

Xu J., Li Z., (2012), A review on Ecological Engineering based Engineering Management, Omega, 40(3), 368378.

Zhai H., Frey H., Rouphail N., (2011), Development of a modal emissions model for a hybrid electric vehicle, Transportation

Research Part D: Transport and Environment, 16, 444-450.

Zhang X., Yamaguchi H., et al., (2006), Analysis of a novel solar energy-powered Rankin cycle for combined power and heat generation using supercritical carbon dioxide, Renewable Energy, 31, 1839-1854. 